This is an electronic reprint of the original article. This reprint may differ from the original in pagination and typographic detail.

Author(s): Pirhonen, Juhani; Rasi, Päivi

Title: $\quad$ Student-generated instructional videos facilitate learning through positive emotions

Year: $\quad 2017$

Version:

Please cite the original version:

Pirhonen, J., \& Rasi, P. (2017). Student-generated instructional videos facilitate learning through positive emotions. Journal of Biological Education, 51(3), 215-227. https://doi.org/10.1080/00219266.2016.1200647

All material supplied via JYX is protected by copyright and other intellectual property rights, and duplication or sale of all or part of any of the repository collections is not permitted, except that material may be duplicated by you for your research use or educational purposes in electronic or print form. You must obtain permission for any other use. Electronic or print copies may not be offered, whether for sale or otherwise to anyone who is not an authorised user. 


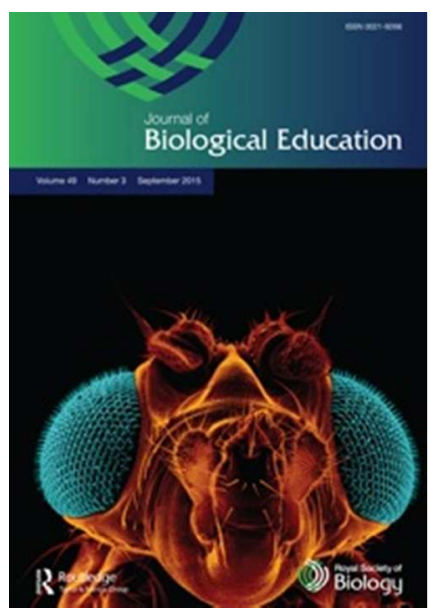

\section{Student-generated Instructional Videos Facilitate Learning through Positive Emotions}

\begin{tabular}{|r|l|}
\hline Journal: & Journal of Biological Education \\
\hline Manuscript ID & RJBE-2015-0117.R1 \\
\hline Manuscript Type: & Research \\
\hline Keywords: & $\begin{array}{l}\text { Academic emotions, Learner-generated instructional video, Learning } \\
\text { journal, Literature review, Multimodal pedagogy }\end{array}$ \\
\hline \multicolumn{2}{|l}{} \\
\hline
\end{tabular}

\section{SCHOLARONE ${ }^{m}$ \\ Manuscripts}




\title{
1 Student-generated Instructional Videos Facilitate Learning through 2 Positive Emotions
}

3

\author{
The central focus of this study is a learning method in which university students \\ produce instructional videos about the content matter as part of their learning \\ process, combined with other learning assignments. The rationale for this is to \\ promote a more multimodal pedagogy, and to provide students opportunities for a \\ more learner-centered, motivating, active, engaging and productive role in their \\ learning process. As such we designed a "video course" where the students \\ needed to produce an instructional video which could be used for university \\ teaching. In addition to producing the video the students needed to write a \\ literature review of the topic of the video and a learning journal. At the end of the \\ course the students filled a questionnaire regarding their learning and emotions \\ during the project. Based on the students' subjective answers it appeared that \\ producing a video, combined with writing the literature review can be an efficient \\ way of learning. Most students found the project emotionally very positive and \\ regarded it motivating to work on a video which they knew will have use in the \\ future. This research suggests that a multimodal video project in a higher \\ education setting enhances learning through increased motivation and positive \\ emotions.
}

\section{Keywords}

Academic emotions; Learner-generated instructional video; Learning journal; Literature review; Multimodal pedagogy

\section{Introduction}

The central focus of this study is a learning method in which university students 
25 produce instructional videos as part of their learning process, combined with other

26 learning assignments. The rationale for this is that when producing videos about the

27 subject matter they are studying, students will learn content as well as transferable skills

28 such as collaboration and problem-solving, and the skills needed in video production

29 (Verran 1992; Jonassen 2000; Jonassen et al. 2003; Shewbridge and Berge 2004;

30 Hakkarainen 2007, 2009). The method is based on the understanding that a more

31 "multimodal pedagogy" (Deacon, Morrison, and Stadler 2005, 75, 83), that is,

32 combining and integrating several representational modes (e.g. text, video, images,

33 voice) into learning materials and assignments may contribute to a more effective

34 learning process (e.g. Peters 2000).

35 Another central rationale for engaging university students in the production of

36 instructional videos is providing them with opportunities for a more learner-centered,

37 motivating, active, engaging and productive role in their learning process. Students can

38 no longer be viewed as only passive consumers of knowledge, but also producers and

39 “prosumers” (Lee and McLoughlin 2007; Multisilta 2014). Students' life-worlds are

40 highly multimodal, and their use of social media in their leisure time is pervasive. The

41 multimodal communication and content creation practices and preferences of these

42 students create challenges for higher education teachers to respond to their life-worlds.

43 An important factor in motivating students is the notion of yielding products which

44 involve a sense of purpose and ownership of what was produced, to cite Bonk and Khoo 
45 (2014, 258), "learners are driven to complete some high-quality, tangible product for 46 others to see, share, use, comment upon, or remix."

47 Very often, as in the case of the present research, the pedagogical rationale for student-

48 generated videos is that the videos will later be re-used as instructional materials

49 (learner-generated content) by their peers (Ellis, Lee, and Tham 2004; Willmott 2014).

50 As such, student-generated videos may serve multiple purposes - they have value to

51 students individually, to peers, as well as possibly to the wider community (Lee and

52 McLoughlin, 2007). Some case studies indicate that student-generated instructional

53 videos have played a supportive role in their peers' learning processes (e.g. Hakkarainen

54 and Vapalahti 2011; Nordstrom and Korpelainen 2011). Nordstrom and Korpelainen

55 (2011) noted that student-produced videos were often enacted with humour and were

56 therefore less authoritative than typical instructional materials. On the other hand, some

57 research shows that additional guidance is needed for students to take full advantage of

58 the content produced by their peers (van Dijk and Lazonder 2013).

59 In higher education settings, in fields other than art, media studies, and communication

60 sciences (see Shewbridge and Berge 2004) students' own video productions are not yet

61 a commonly used learning method. However, a growing number of teachers are

62 motivated to develop and experiment with more innovative assignment types than, for

63 example, the traditional essay (Leedham 2009). Case studies have indicated that 
64 integrating university students' video productions into project-based learning (Hung,

65 Keppell, and Jong 2004), case-based teaching (Hakkarainen, Saarelainen, and Ruokamo

66 2007), and drama pedagogy (Hakkarainen and Vapalahti 2011) has supported students'

67 meaningful learning, and especially its' active, collaborative, contextual, and creative

68 characteristics (see Hakkarainen and Vapalahti 2011). In engineering education it has

69 been demonstrated that allowing students to use non-conventional tools, such as video

70 for preparing their assignments, can promote deep learning of scientific facts, as well as

71 creativity and motivation (Nordstrom and Korpelainen 2011).

72 The emotions which higher education students experience during their learning

73 processes play a central role in their motivation to learn and academic achievement

74 (Pekrun et al. 2002; Op’t Eynde and Turner 2006). It has been shown that higher

75 education students' video production can facilitate learning through positive emotions

76 such as interest, feelings of challenge, and enthusiasm (Hakkarainen 2009; Hakkarainen

77 and Vapalahti 2011; Willmot, Bramhall, and Radley 2011). The so called "academic

78 emotions", that is, emotions that students experience in school or university settings, are

79 linked to academic learning and achievement so that positive emotions predict high

80 achievement, and negative emotions low achievement (Pekrun et al. 2002).

81 However, the existing research on higher education students' video productions is

82 comprised of single case studies. Albeit the results are mostly encouraging, they can 
83 only be considered as tentative, and clearly more research is needed, for example about 84 the possibility of novelty effect (see also Mayberry et al. 2012).

85 The aim of this study was to evaluate whether students' video production could be used 86 to promote learning and understanding of the content matter. The study is based on self87 reports of university biology students who participated in the "video course". Even 88 though the main focus of the course was to teach video production, the deeper learning 89 of the subject matter was also of equally high importance. The research questions were:

90 (1) How did the combination of learning assignments, i.e. literature review, video

91 production and learning journal, work in terms of student performance and learning

92 experiences? (2) According to the students, what kind of a learning experience was the

93 video production? (3) According to the students, what kind of an emotional experience

94 was the video production?

\section{Methods}

\section{The course}

97 This study is based on a 2 ECTS ( 1 ECTS $=27 \mathrm{~h}$ of work) graduate course named

98 "Producing, editing and publishing a video" in the Department of Biological and

99 Environmental Science, University of Jyväskylä, Finland, and the main results are

100 extracted from the questionnaire for the students at the end of the course. The course

101 was organized during the spring semesters of 2011 and 2014, and the first author of this 
102 article acted as the responsible teacher.

103 Both course implementations lasted for five weeks, and they were managed through a

104 learning management system named Optima, widely used in the Finnish universities.

105 The course started with initial lectures of about $3 \mathrm{~h}$ during which the ideas and

106 procedures of the course were explained the students who were given general

107 introduction to shooting a video, covering also copyright issues. This latter part was

108 given by video production specialist from the University IT-support. Before the lecture

109 the students were asked to fill in a short three-item questionnaire in Optima, where we

110 asked the reasons for participation, previous experience of shooting videos and

111 suitability of the time of the course. On the first lecture all students signed an agreement

112 where we asked for permission to use the questionnaire, videos and learning journals for

113 the purpose of writing a scientific article. During the initial lecture we also proposed

114 possible topics for videos but the students were also allowed to choose any kind of

115 relevant topic of their own interest. However, it was highlighted that it should be

116 suitable as instructional video in the university.

117 The course consisted of three learning assignments: 1) literature review of the topic of

118 the video (max 3 pages) and storyboard, 2) learning journals and 3 ) the video. At the

119 end of the course the three components were graded on the scale $0-5$, and the average of

120 them was the grade of the course. Both literature review and storyboard had to be 
121 accepted by the responsible teacher before starting filming the video. The

122 recommendation was to return the review and storyboard within two weeks, and the

123 documents were screened for possible plagiarism with URKUND; this system was

124 available only in 2014.

125 We also wanted to see the learning process through learning journals. The idea was to

126 improve student's learning by forcing them to think and reflect their own learning

127 process in the journals. As such the students were instructed to write the journals at least

128 once a week, and in addition to writing what they have learned also to include any kinds

129 of emotions felt during the process. The journals were graded based on the regularity of

130 writing and also on their contents: how well the students were able to express the

131 learning process.

132 Most videos were made in groups of two students but in both years there was one group

133 of three students, and three students wanted to make the video alone (Table 1). The

134 university borrowed video cameras if needed. In 2014 we also allowed students to use

135 their mobile devices for capturing the footage but all students wanted to use the "real"

136 video camera. The recommendation for the length of the video was no more than 5

137 minutes. The students were given four weeks for independent work (i.e. literature

138 review, storyboard, filming). After this the students were given a lecture by the

139 university's IT specialist about Adobe Premiere Elements 11 as editing software. 
140 Participation to the editing lecture was not obligatory because the students were also

141 allowed to use any other editing software if they wanted. The computer class was

142 reserved for editing for 20 hours, and the teacher was available by phone or e-mail, as

143 he was not with the students all the time.

144 At the final meeting ( $2 \mathrm{~h}$ ) all students were first asked to fill in the research

145 questionnaire (Table 2) and they were given about 30 minutes to do it. After this all

146 participating students and the teachers watched the produced videos and after each

147 video we discussed it. First the students were given the possibility to express their

148 opinions and then the teachers gave their feedback. After watching the videos the

149 students were given some more time to finalize the questionnaire if needed. The videos

150 were downloaded into the University password protected video repository after the

151 course.

\section{Participants}

153 In total 19 students participated the course, 10 students in 2011 and 9 in 2014 (Table 1).

154 The age of the students ranged between 20 and 42 years (mean \pm SD $27.1 \pm 6.1$ years).

155 Most students were from the Department of Biological and Environmental Science but

156 three students came from the Department of Physics and one from the Faculty of ICT.

157 Fourteen participants were postgraduate students, four were undergraduate students and

158 one was doctoral student. In 2011 the course was given in Finnish and in 2014 in 
159 English as four of the students were exchange students from other countries.

\section{The questionnaire}

161 The final 71-item questionnaire consisted of 4 major themes: $i$ ) personal details, ii)

162 teaching, studying and learning in the project, iii) emotions related to studying during

163 the project $i v$ ) videos produced during the project (Table 2). The questionnaire was

164 largely based on a questionnaire originally designed to test the pedagogical model for

165 teaching and meaningful learning (Hakkarainen et al. 2007; Hakkarainen 2009, 2011).

166 The model defines teaching and meaningful learning in terms of 17 process

167 characteristics (e.g. activeness, creativeness, emotional involvement), and their expected

168 outcomes (for a description of the design process of the questionnaire and its previous

169 uses, see Hakkarainen et al. 2007; Hakkarainen 2009, 2011).

170 Under $i i$ we made 37 statements about teaching and studying during the course on the

171 scale $1=$ totally disagree $\ldots 5=$ totally agree, and number 3 was "I do not know". In iii

172 we presented 20 statements related to emotions during the project. These had to be

173 answered on the scale $0=$ not at all $\ldots 4=$ very much, and number 2 was "I do not

174 know". After each statement the student could describe the most important reason(s) for

175 the emotion or to the absence of it. In $i v$ we asked six open ended questions about

176 producing an instructional video, and here we also gave the possibility for any kinds of

177 comments of the course. 


\section{Data analyses}

179 For the statements in $i i$ and $i i i$ we tested the possible statistical difference in the yearly

180 (2011, n=10 and $2014 \mathrm{n}=9$ ) averages for each statement by independent samples $t$-test

181 using SPSS Statistics 20 software. There were no statistical differences $(p>0.05)$ in any

182 statement and consequently the data from these two years were combined $(n=19)$. For

183 each statement we calculated the average and SD. We used also independent samples $t$ -

184 test to compare the average values from the statements in $i i$ and $i i i$ for the students who

185 had no earlier experience in video production $(n=7)$ and those who had $(n=12)$, and

$186 \mathrm{p}<0.05$ was taken as the level of significance. Depending whether Levene's test

187 indicated significant difference in variances, the p-value was selected accordingly

188 ("equal variances assumed / not assumed").

189 We also classified the statements of emotions in iii into positive and negative ones. The

190 following eight emotions were regarded positive: confidence, enthusiasm, relaxation,

191 joy, interest of the subject matter, relief, sense of community and satisfaction. Eleven

192 negative emotions were tension, frustration, anxiety, disappointment, stress, uncertainty,

193 annoyance, feeling of giving up, insufficiency, shame and fatigue/boredom.

194 "Challenge" could be regarded as positive or negative and thus it was left out of this

195 comparison. By using the average values of both positive and negative feeling

196 statements during the project we calculated an overall average value for these two types

197 of feelings and compared them using $t$-test. 
198 In addition, coefficient of variation for each feeling was calculated as

200 Logarithmic regression line was fitted for correlation between CV and the average of 201 each feeling.

\section{Results and discussion}

\section{Combining literature review, video production and learning journal}

204 The literature review is an indispensable part of most academic projects. As such the 205 idea for making the students write a literature review prior to producing the videos was

206 above all to make the students properly familiar with the topic, and to create a sturdy 207 ground for the knowledge (Webster and Watson 2002). There was wide variability in 208 the way how the students performed in writing the literature review. The quality of the

209 review was in many cases better with the more advanced students (postgraduate and

$210 \mathrm{PhD}$ students) than in the groups with undergraduate students. This kind of result was

211 quite expected as the students are trained to search and find relevant literature and write

212 scientific reports typically from the beginning of the second academic year, and at the

213 masters' level the students should have been quite familiar with this procedure. The

214 review was done in groups and as such all members of the group got the same grade

215 from this part. In the groups where group members were from different study levels, the 
216 younger (in academic years) students apparently got advantage of the more advanced

217 students.

218 In some groups the subject matter was too well known by the group members, and no

219 real learning was achieved at this stage. This was the case when the topic was the

220 subject of the $\mathrm{PhD}$ or master thesis. On the other hand in one group the students picked

221 a topic which they knew nothing about and the unawareness of the topic was seen as

222 mistakes and misunderstandings in the review. In the questionnaire the statements

223 related to learning at this stage ("9. Learning about the topic of my video was supported

224 by c) literature review, d) the storyboard") were usually highly agreed (mean 3.89 SD

2251.05 and 3.73 SD 1.09, respectively, Table 2). Only one student totally disagreed about

226 the literature review in this respect and the reason was that he had selected a topic of his

227 thesis and he was very familiar with it.

228 For producing an instructional video we regard it important that the students finish the

229 literature review and storyboard before starting to film the video. This serves as type of

230 quality control and also forces the students to think about the topic deeply and makes

231 them more confident about the subject matter to be presented on the video. Previous

232 research on higher education students as video producers has indicated that when

233 producing videos about a chosen phenomenon, students may skip reading the relevant

234 scientific literature and resort only to their existing knowledge and practical experiences 
235 (Hakkarainen 2009; Hakkarainen and Vapalahti 2011). Therefore, combining more

236 traditional academic assignments with video production is a feasible option for

237 facilitation learning of the subject matter. This would also prevent the pitfall of

238 concentrating too much on the technical rather than conceptual aspects of the video

239 (Schuck and Kearney 2006; Kearney 2011).

240 While the literature review was regarded as a base for conceptual and scientific content

241 of the video, storyboard was regarded as a base for content fluency and technical quality

242 of the video, and the importance of storyboard has also been stressed in earlier research

243 (Kearney 2011). Despite the fact that this point was highlighted for the students it

244 seemed to be difficult for some groups or individuals to get the review and storyboard

245 finished before starting to shoot the video. In three cases the review and storyboard

246 were returned only after the course, and in such cases these did not fulfill their goals of

247 improving the quality of the video's content. As such, it seems that there need to be

248 strict deadlines for returning the review and storyboard if this methodology is being 249 used.

250 The third assignment of the course was to write a learning journal every week, and to 251 enhance students' writing motivation it was graded with the similar weight as the other 252 course assignments. However, this part of the course appeared to be the most difficult 253 for the students. Most students wrote only very little and used the learning journal as a 
254 diary: they just reported very briefly what they had done during that specific day or

255 week but very little or nothing about their learning, thoughts or emotions. The

256 responsible teacher (JP) commented the journals personally for each student after the

257 second week by trying to direct the writing away from just listing what has been done

258 but however the quality of the journals did not really improve.

259 The questionnaire answers indicated wide variability in the usefulness of learning

260 journals in this process. "9. Learning about the topic of my video was supported by

261 learning journals" got an average value of 3.05 (SD 1.22; Table 2) and only one student

262 had graded this statement as 5 (totally agree), but three students had graded this as 1

263 (totally disagree). Also the statement "14. Learning journals helped to understand my

264 own learning" was answered in a quite similar manner (3.11 SD 1.33). In this statement

265 two students totally agreed but four students totally disagreed. One student also

266 mentioned in iii that the reason for the feeling of stress was the learning journal.

267 Learning journal has previously been indicated to be a very powerful tool for increasing

268 biology students' cognitive processes and also performance in exam when compared to

269 traditional writing of scientific reports (McCrindle and Christensen 1995). In that

270 research the writing of learning journals greatly increased students' understanding of the

271 purpose and process of learning, and consequently also the performance in the final

272 exam. The students of the present study were perhaps too concentrated just on 
273 producing their video, and several simultaneous learning assignments possibly

274 decreased their motivation to write the journal while their focus was in the video. Also,

275 as writing of learning journals is not a common assignment in biology courses the

276 students were not familiar with writing the journal and as such they were unable to see

277 the usefulness and purpose of it in the learning process. As such, the students should

278 have been instructed more in detail in writing their journals.

279 From learning point of view this kind of multimodal project can actually improve

280 learning much more than separate assignments. For example Stice (1987) reported how

281 different learning methods affected the retention of information: if the learning method

282 is reading, retention is only $10 \%$, for hearing $26 \%$, for seeing $30 \%$, for seeing and

283 hearing $50 \%$, for saying $70 \%$, and for saying while doing $90 \%$. As such, a video

284 documentary with narration can increase the retention of information drastically instead

285 of, for example, just reading of a textbook. However it must be noted that there are

286 several types of learning styles (Stice 1987), and also each teacher has his/her own

287 preferable learning style. This may be problematic from the student's point of view if

288 the preferred learning style differs greatly from the one that the teacher has.

289 The number of students (19) who participated this research was relatively low.

290 However, the average values of the responses in the questionnaire in ii and iii did not

291 differ significantly between 2011 and 2014. This similarity of responses suggests 
292 reliability of our data. However, the small number and wide age range of participants in

293 the present research does not allow for discussing the potential effect of age on students'

294 performance.

\section{Video production as a learning experience}

296 Filming and editing the video appear good ways of learning as the answers for the

297 statements "9. Learning about the topic of my video was supported by e) shooting the

298 video and f) editing the video" were well agreed, 3.94 (SD 1.25) and 4.0 (1.15),

299 respectively (Table 2), and these values were even slightly higher than those related to

300 learning through literature review and storyboard (see above). The statements " 21.

301 Making the video helped me to understand different aspects related to the topic of the

302 video" and "25. Producing videos made creative thinking possible" were also strongly

303 agreed (4.11 SD 0.94 and 4.58 SD 0.61, respectively, Table 2).

304 There appeared some significant $(\mathrm{p}<0.05)$ differences in responses between the students

305 who had prior experience in producing videos and those who produced videos for the

306 first time. The students who had no prior experience in producing video gave

307 significantly higher scores than the students who had experience for the following

308 statements: " 8 . During the project I learned new issues about producing and publishing

309 a video" (mean \pm SD, $5.0 \pm 0.0$ vs. $4.25 \pm 0.62)$, "9. Learning about the topic of my video

310 was supported by shooting the video" ( $4.67 \pm 0.82$ vs. $3.55 \pm 1.30)$, " 22 . To produce a 
311 video was challenging" (4.43 \pm 0.54 vs. $3.17 \pm 1.12)$ and "23. Studying improved my

312 skills for cooperation and communication" (4.57 \pm 0.54 vs. $3.75 \pm 1.1)$. On the other hand

313 the statement " 19 . The course improved my skills and competences needed in my future

314 employment" got significantly higher scores from students with prior experience in

315 producing videos $(4.25 \pm 0.87)$ than when the students had no prior experience in video

316 production $(3.43 \pm 0.54)$.

317 The question whether the video production brought added value to studying and

318 learning when compared to a more traditional way of learning (reading, writing,

319 discussion) was answered "yes" in 18 cases. Only one student disagreed and his reason

320 was that "if the point is to study the subject matter then making a video takes just extra

321 time and as such does not have added value". The question " 28 . How did you feel about

322 producing a video for instructional material?" got mainly very positive answers such as

323 meaningful, sensible, innovative, (very) fun, interesting, challenging but meaningful,

324 and nice. One student regarded this as a challenge (she did the video alone) and another

325 said that "it was similar to any routine school work".

326 Important point here is that most students felt that what they were doing was something

327 meaningful as the videos can be used for instructional purposes in university teaching,

328 and will not be buried unused as would happen with written reports. It is also well

329 known that teaching is one of the best ways of learning (e.g. Niess and Walker 2010). In 
330 order to be able teach something one must first master the topic (Kugel 1993), and

331 "learning through teaching" has also been regarded important by students in another

332 video production project (Mayberry et al. 2012). In addition, creating videos can be

333 regarded as a divergent form of knowledge expression (Bull and Bell 2010). The

334 students have also been reported to be motivated by knowing that the target audience is

335 their peers (Kearney 2011; Bonk and Choo 2014). Taken together, the students of the

336 present video course were highly motivated to study also the subject matter: first, they

337 knew that the material will have further use and second, they were able to show and

338 express their knowledge in the form of a video. Both inspiration and motivation in a

339 video project have been shown to enhance learning (Willmot, Bramhall, and Radley

340 2011).

341 The quality of the videos was mainly very good, when it comes to their use as

342 instructional videos. Several of the videos could be regarded as mini-documentaries (a

343 day at a fish farm, fish parasites, freshwater pearl mussel, Newton's laws of motion) as

344 they give a general introduction to the topic. Other type of videos were instructional

345 "how to" videos (fish respirometry, sampling of benthic invertebrates, induced breeding

346 of African catfish, measurement of feed intake in fish). The length of the videos varied

347 between c. 2 and 6 minutes. From the technical point of view the students regarded

348 their videos quite successful, e.g. "To be honest, it was not perfect but still it was good".

349 One student who did the video alone was disappointed with the result and finally did not 
350 even consider her video suitable for university teaching (question 27, Table 2). Most

351 students regarded the current format of the course good without needs for changes.

\section{Emotions reported by students}

353 In general, the students found the video production emotionally very positive. The 354 average score of the positive emotions 2.93 (SD 0.57) was significantly higher $355(\mathrm{p}<0.001)$ than for the negative ones $1.00(0.48)$, on the scale 0 to 4 . All positive 356 emotions except "relief" got an average score over two (Figure 1). On the other hand, 357 all emotions which were regarded negative got an average score below 2, and only four 358 of the 11 negative emotions got an average score above 1 (Figure 1). Interestingly, we 359 found a strong negative correlation between the average score of the feeling and average 360 coefficient of variation of each feeling, and the relationship fitted best to a logarithmic 361 regression $\left(R^{2}=0.98\right.$; Figure 2$)$. This indicates, that the smaller the score the bigger is the 362 variability in the emotion in question. For example, in the cases where almost all

363 students felt no negative emotion about the statement in question, totally different

364 responses from just one or two students increase the SD and consequently $\mathrm{CV}$. This

365 result indicates that during the project negative emotions were experienced only seldom

366 while positive emotions were experienced at least to some extent practically with every 367 student.

368 The students with no prior experience in producing videos felt significantly more 
369 enthusiasm during the project (average score 3.86 SD 0.38) than those who had prior

370 experience (3.42 SD 0.51), which may be due to a novelty effect. This result underlines

371 the importance of novelty and learning new skills for learning and emotional

372 experiences, and should encourage teachers to use unconventional methods for teaching.

373 This finding also supports the criticism against the "digital natives" -concept as those

374 students with no prior experience of producing videos responded most positively

375 (Helsper and Enyon 2010). Otherwise there were no differences in emotions when

376 related to the experience in producing videos.

377 Students' video projects have also previously been shown to be emotionally very

378 positive experiences. For example, Hakkarainen and Vapalahti (2011) got almost

379 identical results to ours, regarding college students' emotions on a drama course. Also

380 Willmot, Bramhall, and Radley (2011) reported that $80 \%$ of the engineering students

381 had enjoyed producing an instructional video. However, the present study reveals an

382 interesting finding that positive emotions are rather universal among the students but

383 there is wide variation in negative emotions.

\section{Conclusion}

385 Student-generated instructional videos do not only provide a valuable teaching resource

386 for university teachers but they also provide the students the possibility to learn through

387 an unconventional manner. By producing instructional videos the students need to 
master the subject matter before being able to shoot the video, and the conventional

389 literature review as well as the storyboard helps the students to form a proper ground for

390 shooting footage. The students were motivated to produce videos as they knew that

391 those would be used in the future, and the emotions felt by the students during the

392 project were mostly positive. In the current study we lack direct evidence of improved

393 learning when compared to more traditional ways of teaching and learning, but in

394 general, positive emotions have shown to improve learning. As such the results of this

395 research hopefully encourage higher education teachers to include student-generated

396 instructional video courses in their repertoire of stimulating teaching methods.

397

398

399

400

401

402

403

404

405

406

407

408

409

410

411

412

413

414

\section{References}

Bonk, C. J., and E. Khoo. 2014. Adding Some Tec-variety. 100+ Activities for Motivating and Retaining Learners Online. Indiana, USA: Open World Books.

Bull, G. L., and G. Bell. 2010. Teaching with Digital Video. In Teaching with Digital Video: Watch, Analyze, Create, edited by G. L. Bull, and G. Bell G. 1-11. Eugene: ISTE.

Deacon, A., A. Morrison, and J. Stadler. 2005 Designing for Learning through Multimodal Production: Film Narrative and Spectatorship in Director's Cut. International Journal of Education and Development Using Information and Communication Technology 1 (1): 72-89.

Ellis, G., K. S. Lee, and A. Tham. 2004. Learning engineering mechanics through video production. Proceedings of the 34th ASEE/IEEE Frontiers in Education Conference. www.fie-conference.org/fie2004/papers/1051.pdf.

Hakkarainen, P. 2007. Promoting Meaningful Learning Through the Integrated Use of Digital Videos. PhD thesis, University of Lapland, Finland.

Hakkarainen, P. 2009. Designing and Implementing a PBL Course on Educational Digital Video Production: Lessons Learned from a Design-based Research. Educational Technology Research and Development 57(2): 211-228. 
Hakkarainen, P. 2011. Promoting Meaningful Learning through Video Productionsupported PBL. Interdisciplinary Journal of Problem-based Learning 5(1): 34 53 .

Hakkarainen, P., T. Saarelainen, and H. Ruokamo. 2007. Towards Meaningful Learning through Digital Video Supported Case Based Teaching. Australasian Journal of Educational Technology 23(1): 87-109.

Hakkarainen, P., and K. Vapalahti. 2011. Meaningful Learning through Videosupported Forum-theater. International Journal of Teaching and Learning in Higher Education 23(3): 314-328.

Hargis, J., and S. M. Marotta. 2011. Using Flip Camcorders for Active Classroom Metacognitive Reflection. Active Learning in Higher Education 12(1): 35-44.

Helsper, E., and R. Eynon. 2010. Digital natives: where is the evidence? British Educational Research Journal 36(3): 503-520.

Hung, V. H. K., M. Keppell, and M. S. Y. Jong. 2004. Learners as Producers: Using Project Based Learning to Enhance Meaningful Learning through Digital Video Production. In: Beyond the Comfort Zone: Proceedings of the 21st ASCILITE Conference, edited by R. Atkinson, C. McBeath, D. Jonas-Dwyer, and R. Phillips, 428-436. Perth: Australasian Society for Computers in Learning in Tertiary Education.

Jonassen, D. H. 2000. Computers as Mindtools for Schools: Engaging Critical Thinking. New Jersey: Prentice-Hall.

Jonassen, D .H., J. Howland, J. Moore, and M. Marra. 2003. Learning to Solve Problems with Technology. A constructivist Perspective ( $2^{\text {nd }}$ ed.). Upper Saddle River, NJ: Merrill Prentice Hall.

Kearney, M. 2011. A Learning Design for Student-generated Digital Storytelling. Learning, Media and Technology 36(2): 169-188.

Kugel, P. 1993. How Professors Develop as Teachers. Studies in Higher Education 18(3): 315-328.

Lee, M. J. W., and C. McLoughlin. 2007. Teaching and Learning in the Web 2.0 Era: Empowering Students through Learner-generated Content. International Journal of Instructional Technology and Distance Learning 4(10).

Leedham, M. 2009. From Traditional Essay to "Ready Steady Cook" Presentation: Reasons for Innovative Changes in Assignments. Active Learning in Higher Education 10(3): 191-206. 
Mayberry, J, J. Hargis, L. Boles, A. Dugas, D. O’Neill, A. Rivera, and M. Meler. 2012. Exploring Teaching and Learning Using an iTouch Mobile Device. Active Learning in Higher Education 13(3): 203-217.

McCrindle, A. R., and C. A. Christensen. 1995. The impact of learning journals on metacognitive and cognitive processes and learning performance. Learning and Instruction 5(2): 167-185.

Multisilta, J. 2014. Editorial in Mobile and Panoramic Video in Education. Education and Information Technologies 19(3): 565-567.

Niess, M. L., and J. M Walker. 2010. Digital Video in Mathematics Education In Teaching with Digital Video: Watch, Analyze, Create, edited by G. L. Bull, and G. Bell G. 39-79. Eugene: ISTE.

Nordstrom, K., and P. Korpelainen. 2011. Creativity and Inspiration for Problem Solving in Engineering Education. Teaching in Higher Education 16(4): 439-450.

Op't Eynde, P., and J. E. Turner. 2006. Focusing on the Complexity of Emotion Issues in Academic Learning: A Dynamical Component Systems Approach. Educational Psychology Review 18(4): 361-376.

Pekrun, R., T. Goetz, W. Tizt, and R. P. Perry. 2002. Academic Emotions in Students' Self-regulated Learning and Achievement: A Program of Qualitative and Quantitative Research. Educational Psychologist 37(2): 91-105.

Peters, O. 2000. Digital Learning Environments: New Possibilities and Opportunities. International Review of Research in Open and Distance Learning 1(1).

Schuck, S., and M. Kearney. 2006. Capturing Learning Through Student-generated Digital Video. Australian Educational Computing 21(1): 15-20.

Shewbridge, W., and Z. L. Berge. 2004. The Role of Theory and Technology in Learning Video Production: The Challenge of Change. International Journal on E-Learning. Corporate, Government, Healthcare, and Higher Education 3(1): 31-39.

Stice, J. E. 1987. Using Kolb's Learning Cycle to Improve Student Learning. Engineering Education 77(5): 291-296.

van Dijk, A. M., and A. W. Lazonder. 2013. Scaffolding Students' Use of Learnergenerated Content in a Technology-enhanced Inquiry Learning Environment. Interactive Learning Environments. DOI: 10.1080/10494820.2013.834828 
481 Verran, J. 1992. The Use of Video in Transferable Skills Education for Biology Students 482 I. Production of Pilot Videos. Journal of Further and Higher Education 16: 96$483 \quad 102$.

484 Webster, J., and R. T. Watson. 2002. Analyzing the Past to Prepare for the Future:

485 Writing a Literature Review. MIS Quarterly 26(2): xiii-xxiii.

486 Willmot, P., M. Bramhall, and K. Radley. 2011. Introducing Audio-visual Media for 487 Inspirational Learning and Positive Engagement. In: Proceedings of the SEFI

488 Annual Conference, edited by J. Bernardino, and J. C. Quadrado, 420-426. Lisbon, 489 Portugal.

490 Willmott, C. J. R. 2014. Teaching Bioethics via the Production of Student-generated $491 \quad$ Videos. Journal of Biological Education 49: 127-138.

492 
1

2

3

4

5

6

7

8

9

10

11

12

13

14

15

16

17

18

19

20

21

22

23

24

25

26

27

28

29

30

31

32

33

34

35

36

37

38

39

40

41

42

43

44

45

46

47

48

49

50

51

52

53

54

55

56

57

58

59

60

$493 \quad$ Figure captions.

494 Figure 1. Average score of feelings experienced during the student-generated video

495 project. The feelings were classified as positive or negative, but "challenge" was

496 classified as neutral. The scale for answers was from 0 (not at all) to 4 (very much).

497 Error bars denote SD, $\mathrm{n}=19$.

498 Figure 2. Relationship between the average of a feeling (as in Fig. 1) and the coefficient

499 of variation (CV) of the same feeling. $n=19$ for each data point.

500 
Figure 1. Average score of feelings experienced during the student-generated video project. The feelings were classified as positive or negative, but "challenge" was classified as neutral. The scale for answers was from 0 (not at all) to 4 (very much). Error bars denote SD, $\mathrm{n}=19$. 
1

2

2

3

4

5

6

7

8

9

10

11

12

13

14

15

16

17

18

19

20

21

22

23

24

25

26

27

28

29

30

31

32

33

34

35

36

37

38

39

40

41

42

43

44

45

46

47

48

49

50

51

52

53

54

55

56

57

58

59

60

Table 1. Topics of the videos chosen by students in 2011 and 2014, and the number of students in each group.

\begin{tabular}{ll}
\hline Topics of the student-generated videos & Number of students \\
\hline
\end{tabular}

Induced breeding of African catfish 2

Fish respirometry 2

Sampling of benthic invertebrates in rivers 1

Newton's laws of motion 3

2014

A day at a fish farm 2

Measurement of feed intake in fish $\quad 1$

Fish respirometry (in English) 2

Parasitic stage of freshwater pearl mussel 3

The meaning of roots for plants 1

URL: http://mc.manuscriptcentral.com/rjbe 
Table 2. Questionnaire filled by the students at the end of the video-course. For numerical data mean, standard deviation and the number of responses are presented. For open-ended questions no data are shown. In questions 7-25 the scale for answers was 1 (totally disagree) to 5 (totally agree).

\begin{tabular}{|c|c|c|c|}
\hline & Mean & SD & $\mathrm{N}$ \\
\hline \multicolumn{4}{|l|}{$i$ PERSONAL DETAILS } \\
\hline \multicolumn{4}{|l|}{ 1. Name } \\
\hline 2. Age & 27.1 & 6.1 & 19 \\
\hline \multicolumn{4}{|l|}{ 3. When did you start studying at the University of Jyväskylä? } \\
\hline \multicolumn{4}{|l|}{ 4. Do you have prior experience in producing videos? } \\
\hline Yes. Where? & & & 12 \\
\hline \multicolumn{4}{|l|}{ Encircle the option(s) in which you have experience } \\
\hline a) Writing manuscript / storyboard & & & 4 \\
\hline b) Shooting a video & & & 10 \\
\hline c) Editing & & & 12 \\
\hline d) About something else related to producing videos & & & 3 \\
\hline No prior experience & & & 7 \\
\hline
\end{tabular}

ii TEACHING, STUDYING AND LEARNING IN THE PROJECT

5. How did you familiarize yourself on the topic of your video and writing the manuscript?

a) I did not read anything about it

b) By reading from magazines, journals and/or books

c) From the internet

d) By asking from my friend(s)

e) By going through course materials from other courses $r$

f) By asking from the teacher(s) $\quad 5$

g) By some other means, how?

6. How did you familiarize yourself on the technical aspects of producing videos

a) I did not read anything about it 3

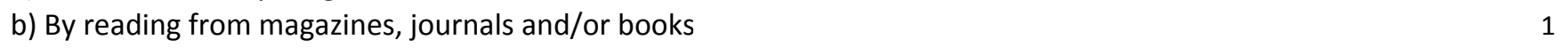

c) From the internet $\quad 12$

d) By asking from my friend(s) $r$

e) By asking from the teacher(s) 3

f) By some other means, how? $\quad 4$

7. Teachers considerably supported my studying and learning:

a) by generating positive ambient $\quad 4.58 \quad 0.61 \quad 19$

b) by giving personal feed back of my working $\quad 3.79 \quad 1.13 \quad 19$

c) by instructing in questions related to the contents of the videos $\quad 4.42 \quad 0.84 \quad 19$

d) by providing clear instructions how to complete the course $\quad 4.58 \quad 0.51 \quad 19$

e) by phrasing clearly the goals of the course $\quad 4.47 \quad 0.70 \quad 19$

f) by giving feedback and instructions quickly enough $\quad 4.53 \quad 0.70 \quad 19$

g) by giving feedback of the essential issues of the video $\quad 4.11 \quad 1.10 \quad 19$

8. During the project I learned:

a) new issues about the topic of my video $\quad 4.16 \quad 1.30 \quad 19$

b) new issues about producing and publishing a video $\quad 4.53 \quad 0.61 \quad 19$

c) group working methods $\quad 3.84 \quad 1.34 \quad 19$

d) problem solving $\quad 3.89 \quad 1.05 \quad 19$

9. Learning about the topic of my video was supported by:
a) familiarizing myself on the topic by reading 
b) familiarizing myself on the topic by other means, how?

$\begin{array}{lll}4.14 & 1.10 \quad 15\end{array}$

c) literature review

$\begin{array}{lll}3.89 & 1.05 & 19\end{array}$

d) storyboard

$\begin{array}{lll}3.74 & 1.10 \quad 19\end{array}$

e) shooting the video

f) editing the video

$\begin{array}{lll}3.94 & 1.25 & 17\end{array}$

g) learning journals

$\begin{array}{lll}4.00 & 1.15 & 19\end{array}$

$\begin{array}{lll}3.05 & 1.22 & 19\end{array}$

10. I had the possibility to study on my own personal way

11. When studying I was able to use my earlier knowledge of the topic of the video

$\begin{array}{lll}4.11 & 1.02 & 18\end{array}$

$\begin{array}{lll}4.11 & 1.24 & 19\end{array}$

12. During the course I was able to apply my earlier practical experiences

$\begin{array}{lll}4.42 & 0.84 & 19\end{array}$

13. I had the possibility to evaluate my learning during the course

$\begin{array}{lll}4.26 & 0.81 & 19\end{array}$

14. Learning journals helped to understand my own learning

15. Studying in this course made it possible to achieve my personal goals

$\begin{array}{lll}3.11 & 1.33 & 19\end{array}$

16. Students were committed to work together

17. What I learned during the course can be used later in other instances

$\begin{array}{lll}3.89 & 1.15 & 19\end{array}$

$\begin{array}{lll}4.21 & 1.18 & 19\end{array}$

$\begin{array}{lll}4.53 & 0.61 & 19\end{array}$

18. The course increased my understanding about what I had learned earlier

$\begin{array}{lll}4.00 & 0.88 & 19\end{array}$

19. The course improved skills and competencies needed in my future employment

$\begin{array}{lll}3.95 & 0.85 & 19\end{array}$

20. The role of the student was to actively search, evaluate and apply information

$\begin{array}{lll}4.26 & 0.81 & 19\end{array}$

21. Making the video helped me to understand different aspects related to the topic of the video

$\begin{array}{lll}4.11 & 0.94 & 19\end{array}$

22. To produce a video was challenging

$\begin{array}{lll}3.63 & 1.12 \quad 19\end{array}$

23. Studying improved my skills for

a) problem solving

b) critical thinking

c) acquiring and evaluating information

d) co-operation and communication

24. It was possible for me to affect the contents and execution of the video

25. Producing videos made creative thinking possible

$\begin{array}{lll}3.63 & 0.90 \quad 19\end{array}$

$\begin{array}{lll}3.68 & 0.95 & 19\end{array}$

$\begin{array}{lll}3.79 & 0.79 \quad 19\end{array}$

$\begin{array}{lll}4.05 & 0.97 & 19\end{array}$

$\begin{array}{lll}4.74 & 0.56 \quad 19\end{array}$

$\begin{array}{lll}4.58 & 0.61 \quad 19\end{array}$

iii FEELINGS RELATED TO STUDYING DURING THE PROJECT

See Figure 1

iv VIDEOS PRODUCED DURING THE PROJECT

26. Were the videos produced during the course suitable for their purpose, that means can they be used for university teaching?

a) Yes

b) No

27. Did the video production bring added value to your studying and learning? Compare the situation e.g to a course where the topic of the video would have been treated on a more traditional way, such as reading, writing and discussions.

a) Yes

b) No

28. How did you feel about producing a video for teaching material?

29. How would you estimate the technical success of your video?

30. Would you still be ready to produce a video as a part of your studies for teaching material?

a) Yes

b) No

31. How would you change the course or is this a good format to do it?

32. Open word (anything related to the course) 